\title{
Short-Term Changes in Gut Microflora and Intestinal Epithelium in X-Ray Exposed Mice
}

\author{
Takakiyo Tsujiguchi, Masaru Yamaguchi, Kanako Yamanouchi \\ Graduate School of Health Sciences, Hirosaki University, Hirosaki, Japan
}

\section{Original Research}

Received August 31, 2020

Revision November 6, 2020

Accepted November 28, 2020

\section{Corresponding author:}

Kanako Yamanouchi

Graduate School of Health Sciences, Hirosaki University, 66-1 Hon-cho, Hirosaki 036-8564, Japan

E-mail: kanako.8@hirosaki-u.ac.jp

(iD https://orcid.org/0000-0002-2692-0396

This is an open-access article distributed under the terms of the Creative Commons Attribution License (http://creativecommons.org/licenses/by-nc/4.0), which permits unrestricted use, distribution, and reproduction in any medium, provided the original work is properly cited.

Copyright $\odot 2020$ The Korean Association for Radiation Protection

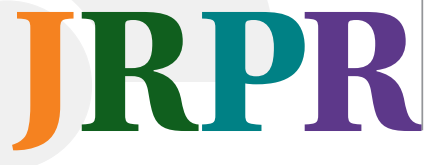

Background: Gut microflora contributes to the nutritional metabolism of the host and to strengthen its immune system. However, if the intestinal barrier function of the living body is destroyed by radiation exposure, the intestinal bacteria harm the health of the host and cause sepsis. Therefore, this study aims to trace short-term radiation-induced changes in the mouse gut microflora-dominant bacterial genus, and analyze the degree of intestinal epithelial damage.

Materials and Methods: Mice were irradiated with 0, 2, 4, 8 Gy X-rays, and the gut microflora and intestinal epithelial changes were analyzed 72 hours later. Five representative genera of Actinobacteria, Firmicutes, and Bacteroidetes were analyzed in fecal samples, and the intestine was pathologically analyzed by Hematoxylin-Eosin and Alcian blue staining. In addition, DNA fragmentation was evaluated by the TdT-mediated dUTP nick-end labeling (TUNEL) assay.

Results and Discussion: The small intestine showed shortened villi and reduced number of goblet cells upon $8 \mathrm{~Gy}$ irradiation. The large intestine epithelium showed no significant morphological changes, but the number of goblet cells were reduced in a radiation dose-dependent manner. Moreover, the small intestinal epithelium of $8 \mathrm{~Gy}$-irradiated mice showed significant DNA damaged, whereas the large intestine epithelium was damaged in a dose-dependent manner. Overall, the large intestine epithelium showed less recovery potential upon radiation exposure than the small intestinal epithelium. Analysis of the intestinal flora revealed fluctuations in lactic acid bacteria excretion after irradiation regardless of the morphological changes of intestinal epithelium. Altogether, it became clear that radiation exposure could cause an immediate change of their excretion.

Conclusion: This study revealed changes in the intestinal epithelium and intestinal microbiota that may pave the way for the identification of novel biomarkers of radiation-induced gastrointestinal disorders and develop new therapeutic strategies to treat patients with acute radiation syndrome.

Keywords: Acute Radiation Syndrome, Gastrointestinal Disorder, Gut Microflora, Lactic Acid Bacteria, Sepsis

\section{Introduction}

The human intestinal tract has an ecosystem composed of 100 trillion bacteria, collectively called intestinal flora [1]. Intestinal flora has an important role on the host nutritional metabolism and the development of the immune system. However, it can also contribute for the progression of diabetes and obesity, with several reports recently published describing the close relationship between flora intestinal and health [2-4]. The symbiosis between humans and enterobacteria is maintained by physical and chemical barriers in the intestinal mucosa $[5,6]$. The physical intestinal barrier consists 
of tight and adherence junctions, which are maintained by the close association of multiple molecules. The chemical intestinal barrier consists of a mucous layer based on mucins secreted by goblet cells. This mucus layer serves as a habitat for intestinal bacteria and it contains digestive enzymes and immunoglobulins, such as immunoglobulin A (IgA), that have key roles in the defense against pathogens that enter the intestinal tract $[7,8]$. These intestinal barriers are the reason why the living body maintains a symbiotic relationship with bacteria and still ensures a healthy status.

When the intestinal barrier function is impaired, the symbiotic relationship between the host and bacteria is disrupted, and the intestinal bacteria may endanger the health of the host. For example, tissues and organs with high differentiation potential, such as hematopoietic tissues and digestive organs, can become instable upon exposure to high doses of radiation $[9,10]$. In fact, patients with acute radiation syndrome (ARS) due to 4 Gy or more radiation exposure have died due to sepsis caused by gastrointestinal disorders [11, 12]. It was also reported in clinical cases that the intestinal flora became populated by Bacteroides spp. after radiotherapy for pelvic tumors [13]. Therefore, radiation exposure seems to have a significant effect on the intestinal flora balance.

A better understanding of intestinal flora changes in radiation-exposed individuals, as well as identification of bacterial genus exhibiting characteristic changes, may contribute to the development of radiation emergency medicine for extreme situations of nuclear terrorism and nuclear disasters. Specifically, it may lead to the discovery of new early exposure dose biomarkers and the design of treatment methods for radiation-induced gastrointestinal disorders [14].

In this study, to obtain data that may contribute to ARS treatment strategies, mice were irradiated with a dose of $\mathrm{X}$ rays, which is the turning point of ARS severity advocated by the International Atomic Energy Agency [15], and the consequent changes in their intestinal flora and damage to the intestinal epithelium were analyzed.

\section{Materials and Methods}

\section{Animal Experimentation}

Seven-week-old C57BL/6Njcl male mice (CLEA Japan, Tokyo, Japan) were used as the experimental model. After an acclimatization period of one week, the 8-week-old mice were whole body irradiated with 2, 4, and 8 Gy X-rays using an MBR-1520 R-3 X-ray irradiation apparatus (Hitachi, Tokyo,
Japan). Irradiation conditions were 1 Gy per minute, with a tube voltage of $150 \mathrm{kV}$, current of $20 \mathrm{~mA}$, and a $0.5 \mathrm{~mm} \mathrm{Al}+$ $0.3 \mathrm{~mm} \mathrm{Cu}$ filter. Four mice were used in each experimental group. Before (0 hour) and after (2, 6, 12, 24, 48, and 72 hours) $\mathrm{X}$-ray irradiation, 4-5 grains of feces excreted by the mice were collected, frozen, and stored at $-80^{\circ} \mathrm{C}$. After 72 hours of observation, the mice were immediately euthanized by cervical dislocation, and the small and large intestines were collected for pathological analysis. Additionally, a preliminary experiment was conducted before starting this experiment. We confirmed that only 8 Gy of 0, 2, 4, 8 Gy irradiation group had $0 \%$ 30-day survival rate and 0-4 Gy irradiation group had $100 \%$ survival rate. Mice non-exposed to radiation were used as controls. The animal experiments were conducted in compliance with the guidelines of laboratory animal use of the Hirosaki University (approval number: G17003).

\section{Pathological Analysis of the Intestinal Tract}

The small intestine and the large intestine were fixed with $10 \%$ buffered formalin solution, embedded in paraffin, and used to prepare a block for thin sectioning. The tissue sections were stained with Hematoxylin-Eosin (H\&E), Alcian blue, and TUNEL (TdT-mediated dUTP nick-end labeling). $H \& E$ staining was used to measure the length from the crypt of the small intestine to the tip of the villi. The thickness of the large intestine epithelium was measured using an eyepiece micrometer. Cells stained with Alcian blue were measured for 10 villi per slide and averaged $(n=4)$ to determine the number of goblet cells. The data is presented as mean \pm standard deviation.

TUNEL staining was performed using the DeadEnd Fluorometric TUNEL System (Promega, Madison, WI, USA). Images were captured using LSM710 confocal microscope (Zeiss, Oberkochen, Germany) and analyzed by ImageJ software (https://imagej.nih.gov/). In the image analysis, the ratio between the area stained with Fluorescein-12-dUTP showing the fragmented DNA and the area stained with DAPI (4',6-diamidino-2-phenylindole) was calculated per each irradiation group and compared.

\section{Fecal DNA Extraction and Relative Quantification of Intestinal Flora}

Fecal DNA was extracted from mouse stool samples by the NucleoSpin DNA Stool kit (Takara Bio, Kusatsu, Japan) as per the manufacturer's instructions. Six primer sets (Table 1) were prepared to analyze the changes in the abundance of intesti- 
Table 1. List of Primers Used in This Study

\begin{tabular}{|c|c|c|c|}
\hline Target & Primer $\left(5^{\prime}-3^{\prime}\right)$ & $\begin{array}{l}\text { Product } \\
\text { length } \\
\text { (bp) }\end{array}$ & $\begin{array}{c}\text { Annealing } \\
\text { temperature } \\
\left({ }^{\circ} \mathrm{C}\right)\end{array}$ \\
\hline All bacteria & $\begin{array}{l}\text { GCCTAACACATGCAAGTCGA } \\
\text { GTATTACCGCGGCTGCTGG }\end{array}$ & 472 & 60 \\
\hline $\begin{array}{l}\text { Lactobacillus } \\
\text { spp. }\end{array}$ & $\begin{array}{l}\text { TGGAAACAGRTGCTAATACCG } \\
\text { GTCCATTGTGGAAGATTCCC }\end{array}$ & 232 & 62 \\
\hline $\begin{array}{l}\text { Bifidobacterium } \\
\text { spp. }\end{array}$ & $\begin{array}{l}\text { AGGGTTCGATTCTGGCTCAG } \\
\text { CATCCGGCATTACCACCC }\end{array}$ & 156 & 62 \\
\hline $\begin{array}{l}\text { Enterococcus } \\
\text { spp. }\end{array}$ & $\begin{array}{l}\text { СCCTTATTGTTAGTTGCCATCATT } \\
\text { АCTCGTTGTACTCCCATTGT }\end{array}$ & 144 & 61 \\
\hline $\begin{array}{l}\text { Clostridium } \\
\text { coccoides } \\
\text { group }\end{array}$ & $\begin{array}{l}\text { AAATGACGGTACCTGACTAA } \\
\text { CTITGAGTTCATTCTTGCGAA }\end{array}$ & 440 & 60 \\
\hline $\begin{array}{l}\text { Bacteroides } \\
\text { spp. }\end{array}$ & $\begin{array}{l}\text { GTCAGTTGTGAAAGTTIGC } \\
\text { CAATCGGAGTTCTTCGTG }\end{array}$ & 127 & 60 \\
\hline
\end{tabular}

nal flora by real-time polymerase chain reaction (PCR) [16, 17] with the Power SYBR Green Master Mix (Thermo Fisher Scientific, Waltham, MA, USA) and the Step One Plus instrument (Applied Biosystems, Waltham, MA, USA). Each cycle threshold (CT) value of the targeted bacteria was corrected by the CT value for the "all bacteria" PCR product, and compared with the respective CT value before irradiation to determine the relative abundance ( $\triangle \Delta \mathrm{CT}$ method). The PCR conditions were 40 cycles of thermal denaturation at $95^{\circ} \mathrm{C}$ for 15 seconds, annealing for 30 seconds, and elongation at $80^{\circ} \mathrm{C}$ for $30 \mathrm{sec}-$ onds. The annealing temperature was set for each primer as indicated in Table 1. CT values of all fecal DNA samples were measured thrice with triplicates. Relative bacteria frequency is indicated as mean \pm standard deviation.

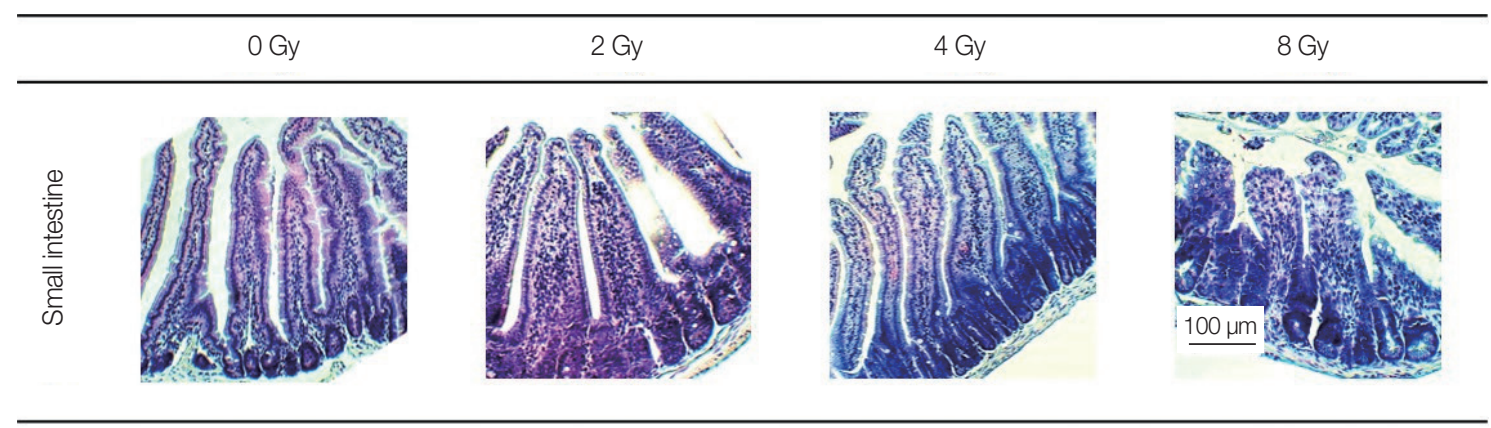
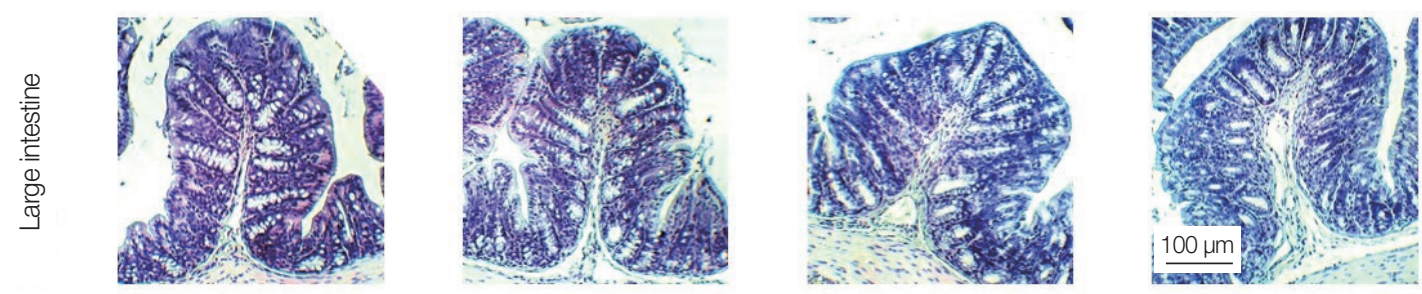

A
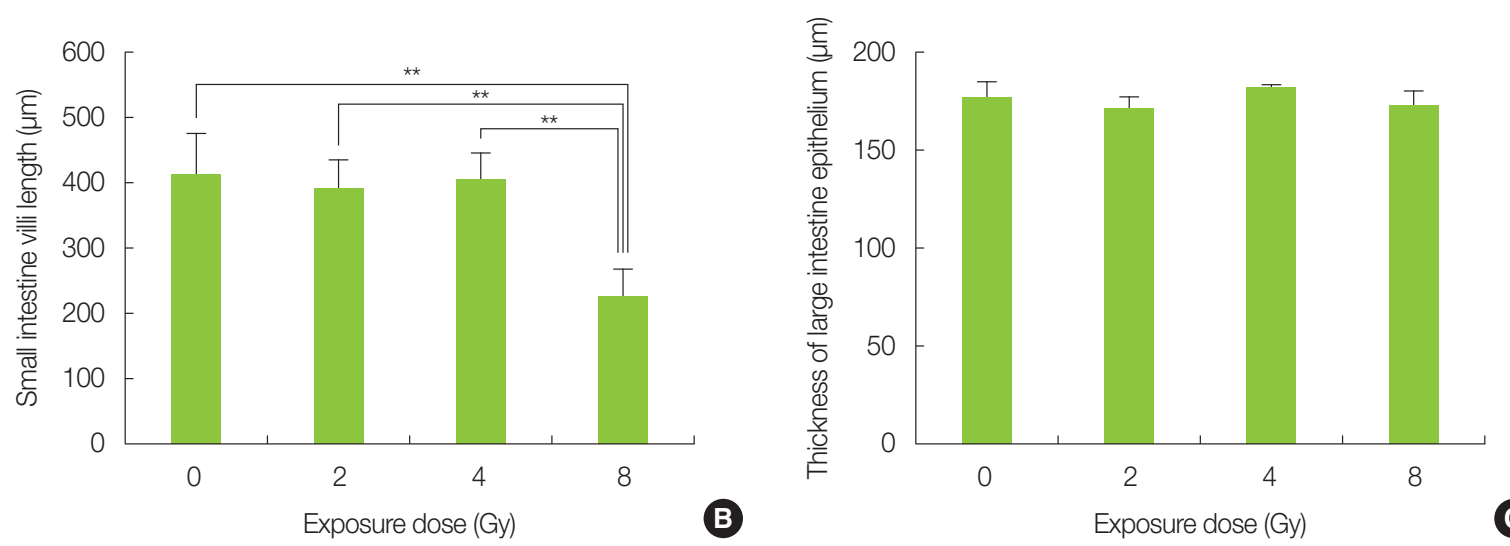

Fig. 1. Analysis of small intestinal villi length and large intestine epithelial thickness using H\&E (Hematoxylin-Eosin) staining. (A) Representative image of each radiation-exposed group. (B) The length of small intestinal villi in the 8 Gy irradiation group was significantly decreased compared with non-irradiated mice $\left({ }^{\star *} p<0.01\right)$. (C) No significant difference was observed between the non-irradiated group and the irradiated groups concerning the thickness of the large intestine epithelium. The data is presented as mean \pm standard deviation. 


\section{Statistical Analysis}

Intestinal flora changes were evaluated by the Student $t$-test and one-way analysis of variance (ANOVA) test compare relative values before and after irradiation with the Origin 8.1 statistical analysis software (OriginLab, Northampton, MA, USA). Results of $p$-value $<0.05$ were considered statistically significant.

\section{Results and Discussion}

\section{Pathological Analysis of the Intestine}

H\&E staining results of intestine samples collected 72 hours after irradiation are shown in Fig. 1A. The villi length of the small intestine in the 2 and 4 Gy-irradiated groups was about
$400 \mu \mathrm{m}$, which was similar to the non-irradiation control group. However, in 8 Gy-irradiated mice, the villi length was significantly shorter $(227.0 \pm 39.7 \mu \mathrm{m})$ than in control mice, by $\sim 180 \mu \mathrm{m}$ or more (Fig. 1B). No significant difference in the thickness of colonic epithelium was observed between the non-irradiated and the 2-8 Gy irradiated groups (Fig. 1C).

A previous pilot study confirmed that under the irradiation conditions used in these experiments, the 30-day survival rate of 2-4 Gy-irradiated mice was $100 \%$, whereas for those exposed to $8 \mathrm{~Gy}$ irradiation group was $0 \%$ (data not shown). The small intestinal epithelium did not show morphological changes upon non-lethal 2-4 Gy irradiation, whereas significant damage was caused by $8 \mathrm{~Gy}$ irradiation. In contrast, the colonic epithelium showed no morphological changes when

\begin{tabular}{llll}
\hline 0 Gy & 2 Gy & 4 Gy & Gy \\
\hline
\end{tabular}
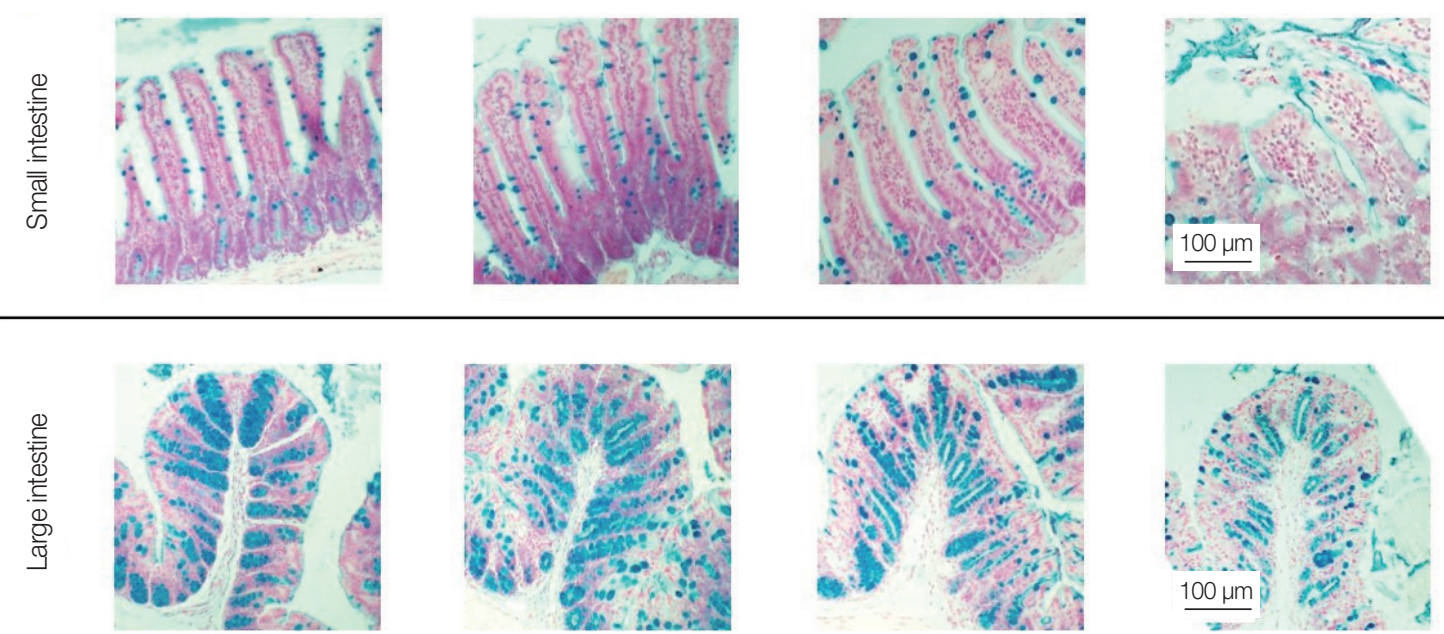

A
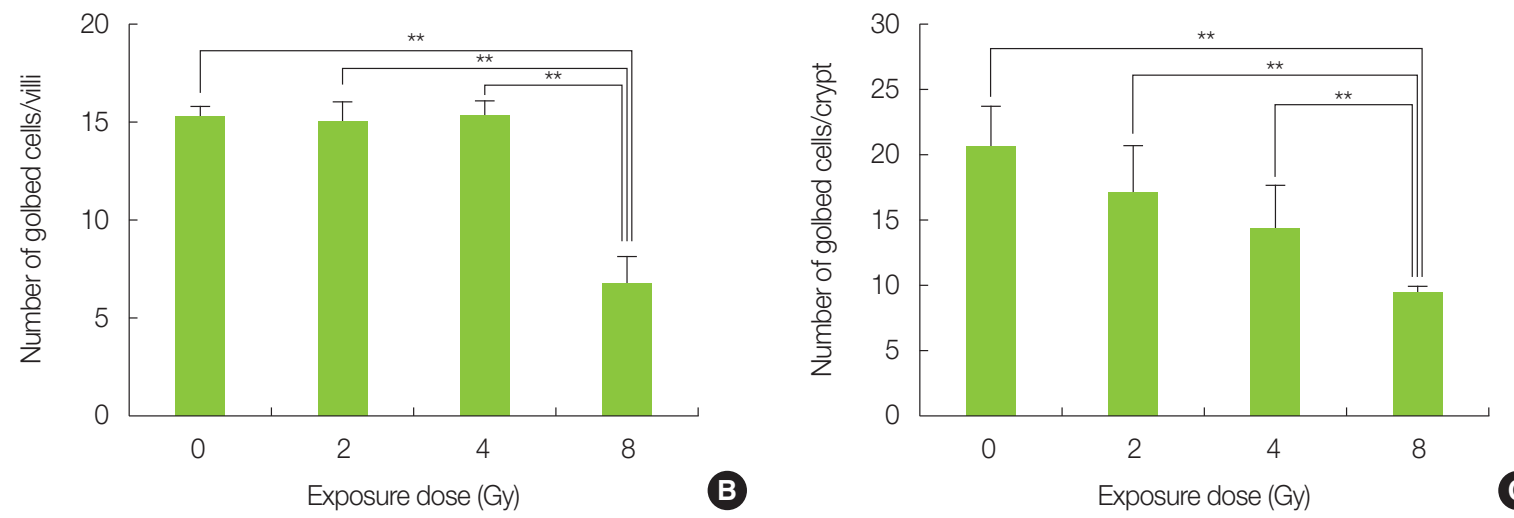

Fig. 2. Analysis of goblet cells by Alcian blue staining. (A) Representative image of each radiation-exposed group. (B) The number of goblet cells in the small intestine of the 8 Gy-irradiated mice was significantly decreased compared with non-irradiated mice $\left({ }^{\star \star} p<0.01\right)$. $(C)$ The number of goblet cells in the large intestine of the 8 Gy irradiation group was significantly reduced compared with the control group $\left.{ }^{* *} p<0.01\right)$. The data is presented as mean \pm standard deviation. 
exposed to lethal X-ray doses.

Alcian blue staining result are shown in Fig. 2A. In the small intestinal epithelium, the number of goblet cells stained was approximately 15 in the non-irradiated, 2 and 4 Gy-irradiated groups, respectively, whereas it was $6.7 \pm 1.4$ in 8 Gy-irradiated mice. A significant decrease in the 8 Gy irradiation group suggested that the mucin secretory function was impaired (Fig. 2B). The number of goblet cells in the large intestine epithelium tended also to decrease with increasing irradiation dose, with $17.0 \pm 7.8$ cells in the $8 \mathrm{~Gy}$ irradiation group that was significantly lower than the $0-4$ Gy irradiation mice. In addition, goblet cells contracted in all irradiation groups, resulting in an empty space between cells (Fig. 2C).

TUNEL staining results are shown in Fig. 3A. Analysis of the small intestine confirmed that the 8 Gy-irradiated group had more cells with fragmented DNA as compared with the non-irradiated and the 2-4 Gy-irradiated groups (Fig. 3B). The TUNEL-positive cells were concentrated in the basal portion of the intestinal epithelium. Moreover, fragmented DNA was found to increase in a dose dependent manner in the large intestine (Fig. 3C). In particular, the 8 Gy irradiation group showed significantly more TUNEL-positive cells at the base of the colon epithelium. Since the intestinal epithelial stem cells, which hold differentiation potential, are enriched at the base of the small intestine and colon epithelium, it is possible that intestine was also strongly damaged in this study, as shown in previous reports $[18,19]$. The difference in DNA damage tendency seen between the small intestine and the
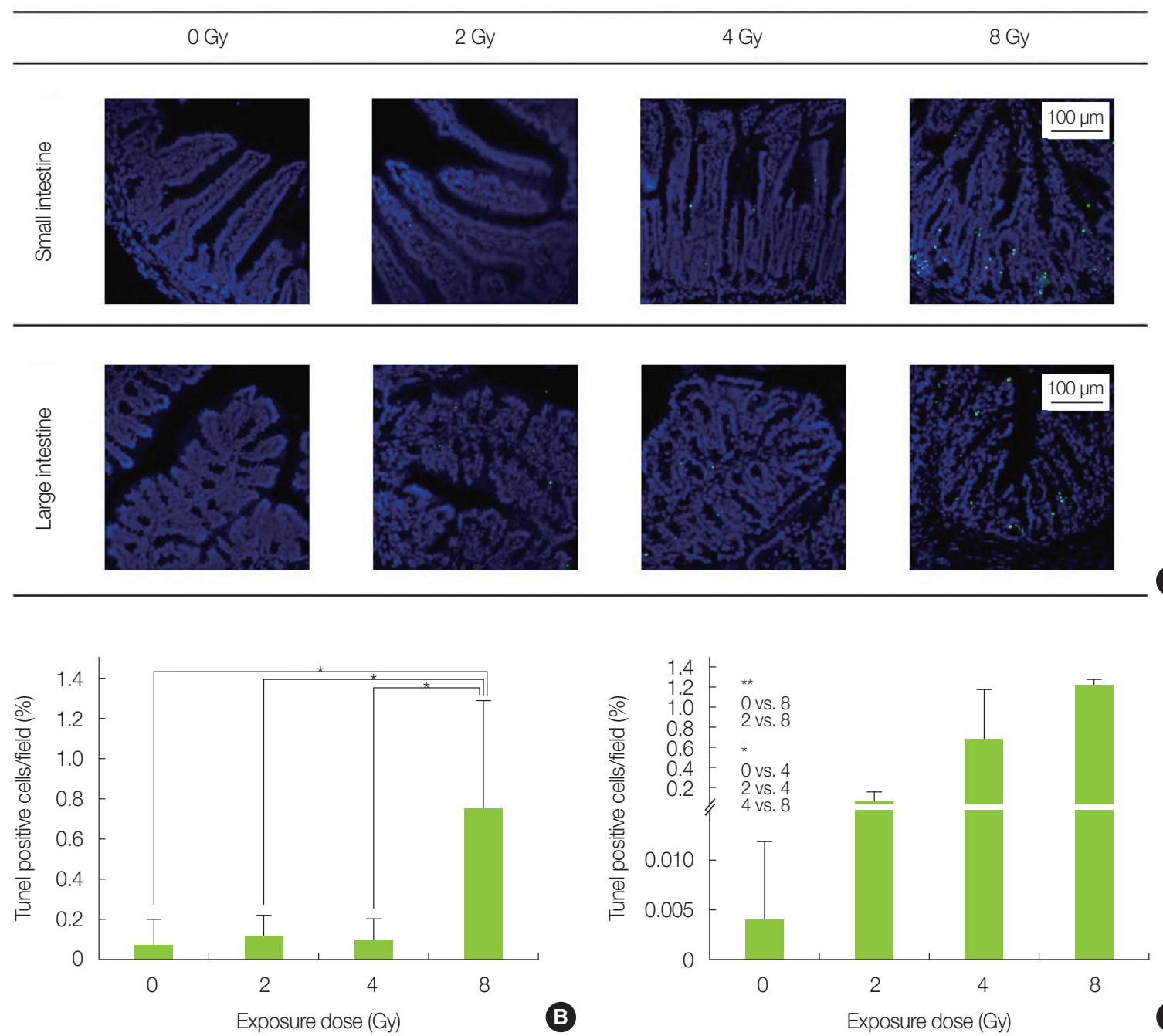

Fig. 3. DNA fragmentation analysis in the small and large intestine by TUNEL (TdT-mediated dUTP nick-end labeling) staining. (A) Representative image of each radiation-exposed group. (B) Percentage of cells showing fragmented DNA in the small intestinal epithelium increased significantly in 8 Gy-irradiated mice $\left({ }^{*} p<0.05\right)$. (C) Percentage of cells showing fragmented DNA in the colon epithelium was significantly increased in 8 and 4 Gy-irradiated mice $\left({ }^{*} p<0.05,{ }^{* *} p<0.01\right)$. The data is presented as mean \pm standard deviation. 
large intestine, which is in agreement with a study of Otsuka et al. [20], is presumed to depend on their different DNA repair efficiency.

\section{Relative Quantification of Intestinal Bacteria}

Relative quantification of intestinal bacteria revealed significant changes on various intestinal bacteria in irradiated mice (Fig. 4). The intestinal bacterial flora showed large fluctuations in lactic acid bacteria groups, including Lactobacillus, Bifidobacterium, and Enterococcus, caused by X-ray irradiation. No dose-dependent change was observed in any of these bacteria; however, it was confirmed that Lactobacillus markedly decreased after 6 to 12 hours of 2-4 Gy irradiation compared with before irradiation (Fig. 4A). In 8 Gy-irradiated mice, the lactic acid bacteria group (Lactobacillus, Bifidobacterium, and Enterococcus) showed a marked frequency increase 2 hours immediately after irradiation (Fig. 4A-4C).
In addition, a significant increase in the amount of Bifidobacterium present in the feces was confirmed in the 4 Gy irradiation group (Fig. 4B). Next, Bacteroides, which is the dominant bacterium of the intestinal microbiota, was not significantly changed in the non-irradiated and the 2-4 Gyirradiated groups, whereas the $8 \mathrm{~Gy}$ irradiation group showed increased amount of Bacteroides excreted immediately after irradiation (Fig. 4D); however, individual differences were noted within mice. In contrast, Clostridium showed a large diurnal variation in the non-irradiated group and smaller variation in the 2-8 Gy-irradiated groups (Fig. 4E).

It is generally considered that bacterial groups are resistant to radiation and are not so affected by irradiation [21, 22]. However, in this study, it was possible to confirm irradiationinduced changes in the intestinal flora, such as decrease or increase in excretion of lactic acid bacteria, and decrease in diurnal fluctuation of Clostridium. These changes can possi-

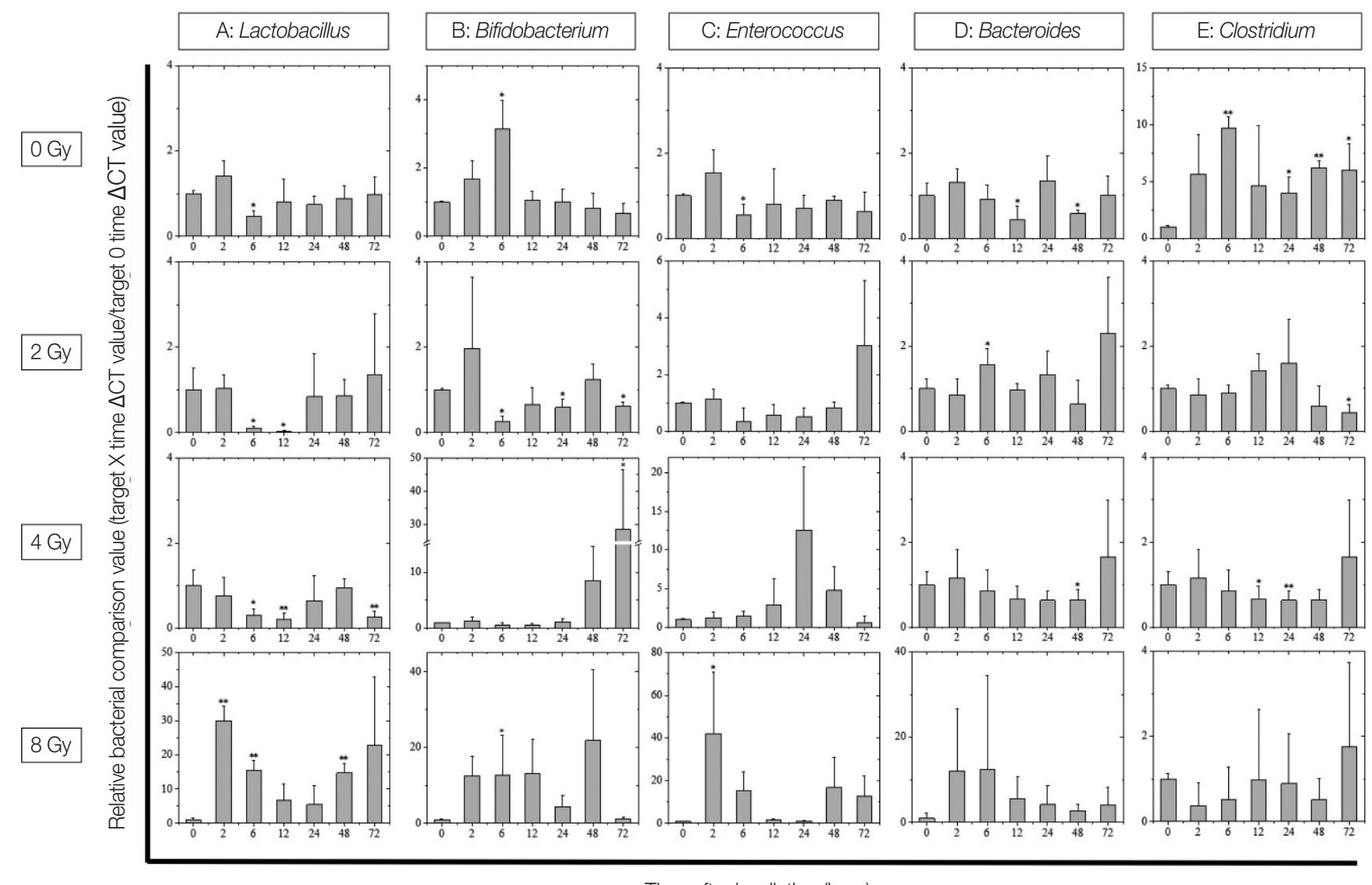

Time after irradiation (hour)

Fig. 4. Changes in the intestinal flora after X-ray irradiation. Displayed from the top in the following order: non-irradiated, 2, 4, and 8 Gy-irradiated groups. The $\mathrm{X}$-axis of each graph shows the time after irradiation and the $\mathrm{Y}$-axis shows the relative bacterial comparison value (target $\mathrm{X}$ hours $\Delta \Delta \mathrm{CT}$ value/target 0 hour $\Delta \Delta \mathrm{CT}$ value). Comparison of (A) Lactobacillus, (B) Bifidobacterium, (C) Enterococcus, (D) Bacteroides, and (E) Clostridium expression in fecal samples from mice before and after $X$-ray irradiation $\left({ }^{\star} p<0.05,{ }^{* \star} p<0.01\right)$. The data is presented as mean \pm standard deviation. 
bly be explained by the fact that bacteria may also suffer DNA damaged due to radiation, which would cause them to lose differentiation potential. However, we believe that the main reason behind these changes may be the alterations in the intestinal epithelium and environment of the host triggered by radiation. For example, the mucin layer secreted by goblet cells is an important nutrient source and habitat layer for lactic acid bacteria in the large intestine, where sugar is deficient [23-26]. Therefore, it is possible that Lactobacillus lost their habitat due to the deteriorated activity of goblet cells by radiation exposure, and their excretion temporarily decreased. The increased excretion of the lactic acid bacteria and Bacteroides in the $8 \mathrm{~Gy}$ irradiation group may be caused by the loss of intestinal epithelium, which is defective in regeneration. In the future, we plan to further explore the interaction between intestinal bacteria and intestinal epithelial function.

\section{Conclusion}

In this study, a short-term follow-up of morphological changes in the intestinal epithelium and changes in the intestinal microbiota of mice exposed to radiation was performed. It was revealed that lactic acid bacteria excretion, including Bifidobacterium and Lactobacillus, fluctuated in radiation-exposed mice even when morphological changes of the intestinal epithelium were not observed. Lactic acid bacteria are known contribute for strengthening the barrier function of the intestinal tract and preventing the transfer of pathogenic bacteria into the bloodstream; therefore, increased excretion of lactic acid bacteria may result in a deteriorated intestinal environment. Nevertheless, the changes observed in this study represent only relative comparisons of the intestinal microflora before and after irradiation. Further studies are necessary to carry out numerical comparisons and viability of the intestinal microbiome by absolute quantification. Such analytical approach may be useful for the identification of novel biomarkers of radiation-induced gastrointestinal disorders and develop new therapeutic strategies to treat patients with ARS.

\section{Conflict of Interest}

No potential conflict of interest relevant to this article was reported.

\section{Acknowledgements}

This study was supported by the Japan Society for the Promotion of Science (JSPS) under the KAKENHI Grants-in-Aid for Scientific Research Program (No. 18K15578).

\section{Author Contribution}

Data curation: Tsujiguchi T, Yamaguchi M, Yamanouchi K. Funding acquisition: Tsujiguchi T. Methodology: Yamaguchi M, Yamanouchi K. Visualization: Yamaguchi M. Writing original draft: Tsujiguchi T. Investigation: Tsujiguchi T, Yamaguchi M. Resources: Yamanouchi K. Software: Tsujiguchi T. Supervision: Yamanouchi K. Validation: Tsujiguchi T.

\section{References}

1. Ley RE, Peterson DA, Gordon JI. Ecological and evolutionary forces shaping microbial diversity in the human intestine. Cell. 2006;124:837-848.

2. Holzapfel WH, Haberer P, Snel J, Schillinger U, Huis in't Veld JH. Overview of gut flora and probiotics. Int J Food Microbiol. 1998; 41:85-101.

3. Flint HJ, Duncan SH, Scott KP, Louis P. Links between diet, gut microbiota composition and gut metabolism. Proc Nutr Soc. 2015;74:13-22.

4. Fay KT, Ford ML, Coopersmith CM. The intestinal microenvironment in sepsis. Biochim Biophys Acta Mol Basis Dis. 2017; 1863(10 Pt B):2574-2583.

5. Groschwitz KR, Hogan SP. Intestinal barrier function: molecular regulation and disease pathogenesis. J Allergy Clin Immunol. 2009;124:3-20.

6. Camilleri M, Madsen K, Spiller R, Greenwood-Van Meerveld B, Verne GN. Intestinal barrier function in health and gastrointestinal disease. Neurogastroenterol Motil. 2012;24:503-512.

7. Ribet D, Cossart P. How bacterial pathogens colonize their hosts and invade deeper tissues. Microbes Infect. 2015;17:173-183.

8. Johansson ME, Hansson GC. Immunological aspects of intestinal mucus and mucins. Nat Rev Immunol. 2016;16:639-649.

9. Dainiak N, Waselenko JK, Armitage JO, MacVittie TJ, Farese AM. The hematologist and radiation casualties. Hematology Am Soc Hematol Educ Program. 2003;2003:473-496.

10. Ding LH, Shingyoji M, Chen F, Hwang JJ, Burma S, Lee C, et al. Gene expression profiles of normal human fibroblasts after exposure to ionizing radiation: a comparative study of low and high doses. Radiat Res. 2005;164:17-26.

11. Ishii T, Futami S, Nishida M, Suzuki T, Sakamoto T, Suzuki N, et al. Brief note and evaluation of acute-radiation syndrome and 
treatment of a Tokai-mura criticality accident patient. J Radiat Res. 2001;42 Suppl:S167-182.

12. Anno GH, Baum SJ, Withers HR, Young RW. Symptomatology of acute radiation effects in humans after exposure to doses of 0.530 Gy. Health Phys. 1989;56:821-838.

13. Yang SH, Yang RS, Tsai CL. Septic arthritis of the hip joint in cervical cancer patients after radiotherapy: three case reports. J Orthop Surg (Hong Kong). 2001;9:41-45.

14. Yamanouchi K, Tsujiguchi T, Sakamoto Y, Ito K. Short-term follow-up of intestinal flora in radiation-exposed mice. J Radiat Res. 2019;60:328-332.

15. International Atomic Energy Agency. Diagnosis and treatment of radiation injuries. Vienna, Austria: International Atomic Energy Agency; 1998.

16. Bartosch S, Fite A, Macfarlane GT, McMurdo ME. Characterization of bacterial communities in feces from healthy elderly volunteers and hospitalized elderly patients by using real-time PCR and effects of antibiotic treatment on the fecal microbiota. Appl Environ Microbiol. 2004;70:3575-3581.

17. Rinttila T, Kassinen A, Malinen E, Krogius L, Palva A. Development of an extensive set of $16 \mathrm{~S}$ rDNA-targeted primers for quantification of pathogenic and indigenous bacteria in faecal samples by real-time PCR. J Appl Microbiol. 2004;97:1166-1177.

18. Potten CS, Merritt A, Hickman J, Hall P, Faranda A. Characterization of radiation-induced apoptosis in the small intestine and its biological implications. Int J Radiat Biol. 1994;65:71-78.

19. Somosy Z, Horvath G, Telbisz A, Rez G, Palfia Z. Morphological aspects of ionizing radiation response of small intestine. Micron. 2002;33:167-178.

20. Otsuka K, Suzuki K. Differences in radiation dose response between small and large intestinal crypts. Radiat Res. 2016;186: 302-314.

21. Daly MJ. A new perspective on radiation resistance based on Deinococcus radiodurans. Nat Rev Microbiol. 2009;7:237-245.

22. Daly MJ, Gaidamakova EK, Matrosova VY, Vasilenko A, Zhai M, Leapman RD, et al. Protein oxidation implicated as the primary determinant of bacterial radioresistance. PLoS Biol. 2007;5:e92.

23. Hooper LV, Midtvedt T, Gordon JI. How host-microbial interactions shape the nutrient environment of the mammalian intestine. Annu Rev Nutr. 2002;22:283-307.

24. Nishiyama K, Ochiai A, Tsubokawa D, Ishihara K, Yamamoto Y, Mukai T. Identification and characterization of sulfated carbohydrate-binding protein from Lactobacillus reuteri. PLoS One. 2013;8:e83703.

25. Ouwehand AC, Salminen S, Isolauri E. Probiotics: an overview of beneficial effects. Antonie Van Leeuwenhoek. 2002;82:279289.

26. Servin AL, Coconnier MH. Adhesion of probiotic strains to the intestinal mucosa and interaction with pathogens. Best Pract Res Clin Gastroenterol. 2003;17:741-754. 